\title{
Impact of Prison Status on HIV-Related Risk Behaviors
}

\author{
Angela L. Hudson · Adeline Nyamathi · \\ Debika Bhattacharya $\cdot$ Elizabeth Marlow \\ Steven Shoptaw $\cdot$ Mary Marfisee $\cdot$ Barbara Leake
}

Published online: 20 May 2009

(C) The Author(s) 2009. This article is published with open access at Springerlink.com

\begin{abstract}
Baseline data were collected to evaluate the effectiveness of interventions on completion of the hepatitis A and B vaccine series among 664 sheltered and streetbased homeless adults who were: (a) homeless; (b) recently ( $<1$ year) discharged from prison; (c) discharged 1 year or more; and (d) never incarcerated. Group differences at baseline were assessed for socio-demographic characteristics, drug and alcohol use, sexual activity, mental health and public assistance. More than one-third of homeless persons $(38 \%)$ reported prison time and $16 \%$ of the sample had been recently discharged from prison. Almost half of persons who were discharged from prison at least 1 year ago reported daily use of drugs and alcohol over the past 6 months compared to about 1 in 5 among those who were recently released from prison. As risk for $\mathrm{HCV}$ and HIV co-infection continues among homeless ex-offenders, HIV/ $\mathrm{HCV}$ prevention efforts are needed for this population.
\end{abstract}

Keywords Homeless - History of incarceration . HIV $\cdot$ HBV

A. L. Hudson

School of Nursing, University of California, Los Angeles, Room 5-141, Factor Building, Los Angeles, CA 90095, USA

A. Nyamathi $(\varangle) \cdot$ E. Marlow $\cdot$ B. Leake

School of Nursing, University of California, Los Angeles, Room 2-250, Factor Building, Los Angeles, CA 90095-1702, USA

e-mail: anyamath@sonnet.ucla.edu

D. Bhattacharya

Division of Infectious Diseases, University of California, Los Angeles, Los Angeles, CA, USA

S. Shoptaw · M. Marfisee

Family Medicine, University of California, Los Angeles, Los Angeles, CA, USA

\section{Introduction}

Incarceration rates in the US are increasing. Currently, 2 million individuals are in jails or prisons in the U.S.; these figures represent an increase of $239 \%$ in incarceration rates over the past 2 decades (Harrison 2003). In California alone, the prisoner population totaled 168,000 in 2005 , and since 1990, it has increased three times faster than the overall adult population (Bailey 2006). Annually, greater than 10 million individuals are released from U.S. jails (Ke 1998) and an additional 600,000 individuals are discharged from state and federal prisons (Travis 2005).

Inmates of U.S. prisons are disproportionately burdened with serious medical conditions, including mental illness (Fazel and Danesh 2002; Teplin 1990; Teplin et al. 1996), substance abuse (Weinbaum et al. 2004), viral hepatitis (Macalino et al. 2004; Ruiz et al. 1999; Solomon et al. 2004) and HIV/AIDS (Bureau of Justice Statistics Bulletin 2005; Hammett et al. 2002). Substance abuse, a risk factor for risky sexual behaviors and the acquisition of HIV and hepatitis, is particularly prevalent among US prisoners. In one survey, $57 \%$ of state prisoners reported the use of illicit drugs in the month before their offense (Weinbaum et al. 2004). In addition, incarcerated persons report more injection drug use and unsafe sexual practices than does the population at large (Glaser and Greifinger 1993). Incarceration has also been associated with increased risk of HIV and hepatitis (Khan et al. 2005; MMWR 2004) acquisition.

Former prisoners are over-represented among the homeless (Bureau of Justice Statistics 1999) and prisoners who are released from incarceration experience a high risk of new onset homelessness (Desai et al. 2000; Martell et al. 1995). Homeless or marginally-housed individuals with a history of incarceration have significantly higher health 
risks than those without this history, including histories of mental illness, psychiatric hospitalization, illicit drug use, and HIV infection (Kushel et al. 2005). Formerly incarcerated persons who are homeless are more likely to have a substance use disorder (SUD), and to experience impoverished social circumstances on reentry to the community, all factors that increase the risk for HIV infection or transmission (Greenberg and Rosenheck 2008a, b; Kushel et al. 2005). Duration of homelessness is also associated with exposure to the criminal justice system: in one study, longer durations of homelessness were associated with histories of arrest (Caton et al. 2005). Homelessness, in turn, increases the subsequent risk for recidivism (Metraux 2004).

Individuals released from prison have difficulties in accessing housing as well as community healthcare services; receipt of such services is associated with receipt of public benefits, health insurance, and social support (Lee et al. 2006). For example, as a result of many state's housing policies, individuals with a criminal record are frequently barred from public housing, thereby further delimiting ex-offenders' access to affordable housing.

Released inmates also face substantial barriers to accessing substance abuse, medical, and mental health treatment programs. In particular, barriers to health care include the absence of discharge planning, insufficient health insurance, and discrimination against ex-offenders (Lee et al. 2006). Homeless individuals also experience obstacles to healthcare, including mental illness, addiction, competing priorities, and lack of health insurance (Gelberg et al. 1997; Kushel et al. 2001). Although a comparison of the receipt of public benefits, such as General Relief, which provides support to indigent populations by Los Angeles County, between homeless individuals with and without histories of incarceration has not been performed, it is expected that issues common to homelessness and incarceration, such as mental illness, substance abuse, and medical comorbidities, would only compound the difficulties in accessing social and health care services in homeless former prisoners.

Although research has identified an association between previously imprisoned homeless individuals and increased health risks (Kushel et al. 2005), there is as yet limited data on the relationship between incarceration, substance abuse, and resource access among homeless persons with and without histories of incarceration. We sought to examine differences in drug and alcohol use and sexual risk behavior, mental and physical health and access to public assistance in three mutually exclusive groups of individuals; those who were homeless and recently ( $<1$ year ago) discharged from prison, those who were homeless and discharged at least 1 year ago, and those who were homeless but never incarcerated.
If homeless ex-offenders are more likely to engage in risky substance abuse and less likely to access public resources, then it might be necessary to design immediate post-release intervention programs for this population, including HIV and hepatitis prevention education, substance abuse treatment, housing and job training programs.

\section{Methods}

\section{Study Design}

Data for this study came from a larger prospective study designed to evaluate the effectiveness of three different interventions on completion of the hepatitis A and B vaccine series among sheltered homeless adults in the Skid Row area of Los Angeles. The intervention period lasted over a six-month period. The data collection period for the entire study was between September 2003 and June 2006. Homeless adults were recruited from homeless shelters, residential recovery programs or from the streets in the Skid Row area of Los Angeles. Participating sites were stratified by type (homeless shelter, residential recovery and street sites) and size, and eligible persons were randomized to one of three treatment programs: the Nurse Case Managed Program with Incentives and Tracking (NCMIT), the Standard plus Incentives and Tracking (SIT) and Standard plus Incentives only (SI). Stratification by type and size of site was performed to equalize randomization across groups.

The framework for the parent intervention study was the Comprehensive Health Seeking and Coping Paradigm (CHSCP) (Nyamathi 1989), which focuses on the implementation of strategies relating to coping, communication skills, and promotion of health-seeking behavior.

\section{Participants}

Eligibility for the parent study included: (1) adult age 1865 , residing in one of 16 participating homeless sites; (2) willingness to undergo hepatitis A virus (HAV), hepatitis B virus (HBV), hepatitis $\mathrm{C}$ virus (HCV) and HIV antibody testing at baseline and at six-month follow-up; (3) willingness to participate in the intervention; and (4) no history of HBV vaccination. This study included 664 participants who did not test positive for HBV antibodies.

\section{Procedure}

This research and all associated materials and flyers were approved by UCLA Human Subjects Protection Committee. Flyers were posted at recruitment sites to inform residents of the study. Following written informed consent to 
screening by interested homeless adults, outreach workers administered a brief questionnaire covering basic sociodemographic characteristics and a hepatitis-related health history designed to assess eligibility for the HAV/HBV vaccination study. Homeless persons determined by the research nurses to be eligible and interested in enrollment into the study completed a second written informed consent followed by pretest counseling and a blood draw for HAV, HBV, HCV and HIV assays for further eligibility consideration. Potential participants were then given referrals to see one of our research nurses stationed at the research site two-weeks later for posttest counseling and test results. Homeless adults found to be HBV negative at the twoweek follow-up (regardless of their HAV/HCV/HIV status), and interested in participating in the study, were then provided final written informed consent for the study. Subsequently, research nurses and outreach workers administered the baseline survey, prior to informing participants of their randomization into one of three programs over a six-month period, ending with a follow-up interview at the sixth month. The research nurses and outreach workers who delivered the intervention were not involved in the baseline or follow-up assessments. Incentives totaling $\$ 5$ were provided to all participants as they completed each dose of the vaccine series. In addition, nominal incentives were provided for completion of the initial blood work and for completion of the baseline and six-month questionnaires.

\section{Measures}

Most instruments utilized in the study had been previously tested, modified, and validated for impoverished and/or homeless African-American, Latino, and White adults (Sherbourne and Stewart 1991; Simpson and Chatham 1995; Stewart et al. 1988). The baseline instruments and measures used in this study are described below.

\section{Socio-demographic Characteristics}

Socio-demographic information including age, gender, ethnicity, education, homeless history, partnership, veteran status, number of lifetime and recent sexual partners, public assistance, and prison status was collected using a structured questionnaire. Public assistance was measured by a one-item "yes/no" question assessing resources such as SSI/SSDI/unemployment income, general relief, and foods stamps. Participants were also asked how many months they had spent in prison; those who reported prison time were queried about the month and year of their last discharge. A derived variable, prison status, characterized participants in terms of recent discharge $(<1$ year) versus past discharge (at least 1 year) versus no history of incarceration. Recent and past discharge were based on the time between the last prison discharge date and the interview date.

\section{Substance Use Behaviors}

The TCU Drug History form measured Drug and Alcohol Use (Simpson and Chatham 1995). It records lifetime and past six-month use of 16 drugs, including methamphetamine, and elicits information about current frequency of non-injection and injection use. This instrument has been validated with men and women with a history of drug addiction, prostitution, and homelessness and revealed twoweek test-retest reliabilities in an acceptable range of .63.71 (Anglin et al. 1996). The 4-item CAGE screener (Ewing 1984) and 2 additional items, "how often did you have a drink containing alcohol in the past 6 months" and "how many drinks containing alcohol did you have on a typical day when you were drinking in the past 6 months" measured lifetime and current alcohol abuse. Sharing/ Cleaning Needles and Other Drug Paraphernalia was measured by 6 items modified from the LA Seroprevalence Study (Ford 1992); these items elicited data on needle sharing and cleaning, sharing other drug equipment, and sharing straws for cocaine and methamphetamine use. Respondents were also asked about their history of smoking cigarettes and whether they attended a drug recovery program in the last 6 months.

Sexual Risk was assessed by number of sexual partners in the last 6 months and if the individual traded sex for money or other things.

Mental Health was assessed with the Center for Epidemiological Studies Depression (CES-D) scale (Radloff 1977). The 20-item self-report instrument is designed to measure depressive symptomology in the general population and has been validated for use in homeless populations (Ritchey et al. 1990). Each item measures the frequency of a symptom on a 4-point response scale from 0 "Rarely or none of the time ( $<1$ day)" to 3 "Most of the time (57 days)". Examples of CES-D items are "I felt depressed," and "I felt fearful." Item scores were summed, giving an overall scale that could range from 0 to 60 . Higher scores indicate more depression. The scale was dichotomized at the customary vale of 16 (Radloff 1977), indicating further need for evaluation of depressive symptoms. The internal reliability in this sample was 0.90 .

Physical Health was measured by physical functioning as assessed by the RAND Functional Status Scale (Health Cost and Services Utilization Study 1995). This 10-item scale examines ability to perform various activities, such as bending or stooping, moving a table, running, walking several blocks. Items were linearly transformed to a scale of 0-100 and a mean-item score was constructed; higher 
scores correspond to better functional status. Cronbach's alpha for the scale in the study was 0.91 .

\section{Statistical Analyses}

Statistical analyses contrasted participants who had never been imprisoned, those who had been discharged from prison at least a year ago and those who had been discharged within the past year. Chi-square tests and analysis of variance (ANOVA) were used to assess overall group differences in socio-demographic characteristics, substance use, mental health and public benefits, depending on whether the variable of interest was categorical or continuous with an approximately normal distribution. For continuous variables, Duncan's multiple range test, with alpha set to .05 , was used for paired comparisons when significant overall differences were found by ANOVA. For categorical variables, we limit multiple testing problems by reporting overall chi-square test results and then describing selected group proportions. Statistical analyses were performed with SAS/STAT (http://www.sas.com).

\section{Results}

\section{Socio-demographic Characteristics}

Based upon self-reported information, the 664 participants were categorized as having never been in prison $(n=412)$, past prison discharge ( $\geq 1$ year) $(n=144)$, or recent discharge from prison $(<1$ year) $(n=108)$. Thus, more than one-third (38\%) reported prison time and $16 \%$ of the sample had been recently discharged from prison. Participants were primarily male (75\%) and Black (70\%). Their mean age was 42.1 (SD 9.0); the average participant had slightly less than 12 years of education. Mean prison time was 47.4 months ( $\mathrm{SD}=51.9$ months), with a range from less than 1 to 336 months. Median time in prison was 28.0 months.

As depicted in Table 1, recently discharged prisoners were younger and less educated than those in each of the other two groups of participants. Less than one-third of this group $(31.5 \%)$ reported public assistance, whereas twothirds of the rest of the sample did so. No differences were noted with respect to veteran status.

Over half of those discharged from prison in the past year had been in residential substance treatment programs during the previous 6 months (Table 2). Recently discharged participants had relatively high rates of lifetime substance use. Almost three-quarters of recent prison discharges reported ever snorting cocaine, while $44 \%$ of those who were never imprisoned did so. One-third (34\%) of persons who were recently discharged from prison likewise
Table 1 Sample Characteristics by Prison Discharge Status

\begin{tabular}{|c|c|c|c|}
\hline \multirow[t]{2}{*}{ Characteristics } & \multicolumn{3}{|c|}{ Percent, or Mean (SD) } \\
\hline & $\begin{array}{l}\text { Never in } \\
\text { prison } \\
(N=412)\end{array}$ & $\begin{array}{l}\text { Past prison } \\
\text { discharge } \\
(N=144)\end{array}$ & $\begin{array}{l}\text { Recent prison } \\
\text { discharge }^{\mathrm{a}} \\
(N=108)\end{array}$ \\
\hline Background & Mean (SD) & Mean (SD) & Mean (SD) \\
\hline Age & $42.6(9.7)$ & $42.7(7.5)$ & $39.5 * *(7.8)$ \\
\hline \multirow[t]{2}{*}{ Education } & $12.1(1.9)$ & $12.0(1.5)$ & $11.4 * * *(1.8)$ \\
\hline & $\%$ & $\%$ & $\%$ \\
\hline Male & $64.8 * * *$ & 88.9 & 94.4 \\
\hline \multicolumn{4}{|l|}{ Ethnicity } \\
\hline Black & 68.9 & 79.9 & 61.1 \\
\hline White & 14.6 & 9.0 & 19.4 \\
\hline Hispanic & 13.8 & 8.3 & 17.6 \\
\hline Other & 2.6 & 2.8 & 1.8 \\
\hline Veteran status & 14.4 & 9.7 & 9.3 \\
\hline Public Assistance & 66.0 & 60.4 & $31.5 * * *$ \\
\hline
\end{tabular}

${ }^{a}$ Recent refers to past twelve-month period

** $P<.01$, ANOVA for overall group differences

*** $P<.001$, chi-square or ANOVA for overall group differences

reported snorting methamphetamine during their lifetime compared to less than one in five of those who were never imprisoned. Persons who were more recently discharged from prison had relatively low rates of daily alcohol use, daily drug use, and daily drug/alcohol use.

No differences were found for numbers of sexual partners in the past 6 months. Greater proportions of both the past and recent ex-prisoners reported high functional status compared to the never-imprisoned group $(X=91$ and 92 vs. 84 , respectively. Depressive symptomotology was found to be high $(\geq 16)$ but not significantly different across the three groups.

\section{Discussion}

This study focused on drug and alcohol use and sexual behaviors, mental and physical health, and access to public assistance in homeless adults. Comparisons were made among homeless adults discharged from prison less than 1 year, those who were homeless and had been discharged at least 1 year ago, and those who were homeless but never incarcerated.

Findings revealed that history of intranasal cocaine and methamphetamine use was highest among recently-discharged ex-offenders. Among those discharged at least 1 year ago, there was generally more past 6 months daily drug and alcohol use compared to recently-released inmates. This finding suggests that, given time to readjust from prison life, drug and alcohol use continues after 
Table 2 Psychological and behavioral risk by prison status

\begin{tabular}{|c|c|c|c|}
\hline \multirow[t]{2}{*}{ Characteristics } & \multicolumn{3}{|c|}{ Percent, or Mean (SD) } \\
\hline & $\begin{array}{l}\text { Never in prison } \\
(N=412)\end{array}$ & $\begin{array}{l}\text { Past prison discharge } \\
(N=144)\end{array}$ & $\begin{array}{l}\text { Recent prison } \\
\text { discharge } \\
(N=108)\end{array}$ \\
\hline & Mean (SD) & Mean (SD) & Mean (SD) \\
\hline Depression & $17.6(12.1)$ & $17.1(11.3)$ & $16.7(11.1)$ \\
\hline Number of sexual partners, past 6 months & $3.1(7.9)$ & $5.1(12.7)$ & $2.5(3.3)$ \\
\hline Functional status & $83.9 * * *(25.5)$ & $90.9(19.4)$ & $92.4(21.3)$ \\
\hline Years smoked cigarettes & $15.0(12.7)$ & $18.4(11.8)$ & $15.2(11.2)$ \\
\hline Substance use & $\%$ & $\%$ & $\%$ \\
\hline Lifetime IDU & 11.2 & 16.7 & 30.6 \\
\hline IDU, past 6 months & 4.9 & 5.6 & 7.4 \\
\hline Ever snorted cocaine & 43.9 & 60.4 & $73.2 * * *$ \\
\hline Ever snorted meth & 18.7 & 22.9 & $33.3 * * *$ \\
\hline Daily alcohol use, past 6 months & 20.2 & 26.4 & $12.0 *$ \\
\hline Daily drug use, past 6 months & 25.5 & 41.7 & $19.4 * * *$ \\
\hline Daily alcohol/Drug use, past 6 months & 32.3 & 47.9 & $21.3 * * *$ \\
\hline Drug recovery program, past 6 months & 14.3 & 27.8 & $53.7 * * *$ \\
\hline
\end{tabular}

${ }^{a}$ Recent refers to past twelvemonth period

$* P<.05$, chi-square for overall group differences

** $P<.01$, chi-square for overall group differences

*** $P<.001$, chi-square test for overall group differences participants also had the lowest rates of daily drug and alcohol use and the highest rate of recent attendance in drug recovery when compared to the remaining study group. Enrollment in treatment soon after release may have had a beneficial impact on the daily drug and alcohol use patterns of recently released inmates. Alternatively, this finding alludes to the idea that a period of incarceration may serve as a period of abstinence from drugs and alcohol for many inmates.

The younger participants' enrollment in substance abuse treatment (SAT) may also be an indication of the increasing emphasis on drug and alcohol treatment during and after incarceration within the legal and correctional systems (Carter et al. 2006; Taxman et al. 2007; Turley et al. 2004). These participants may have benefited from these newer policies in a way that participants released from prison for more than 12 months were unable to. Prisoners discharged into their home communities more than 1 year ago reported the highest use of drugs and alcohol as compared with recently discharged prisoners or their counterparts never in prison. While parole status is not known, one possible explanation is that access to drug and alcohol treatment may have been delimited for prisoners discharged more than 1 year ago.

No differences were noted among the three participant groups in the number of sex partners. Nevertheless, recent literature suggests that formerly incarcerated individuals frequently engage in unsafe sex with multiple partners as a result of both drug use and sex work (Caton et al. 2005; Cooke 2004; Lennings et al. 2006; Masson et al. 2004; Reback et al. 2007; Weiser et al. 2006; White et al. 2006). 
This study also reveals the complex circumstances adults with a dual history of incarceration and homelessness experience in their communities and provide some insight into the inconsistencies of service provision to this population. Data from this study suggests that newly released persons are utilizing public support programs less although they may have an easier time accessing SAT. Increased access to SAT may be related to the recent increase in attention and resources dedicated to continued drug treatment upon release from prison. In contrast, formerly incarcerated individuals who remain in the community for extended periods of time may have increased access to public support and social services but drug and alcohol treatment may no longer be readily available to them, possibly as a result of completing parole. Therefore, two vital resources, drug and alcohol treatment and financial support, are sporadically and inconsistently offered, making it difficult for homeless, former prisoners to address one of their greatest HIV-risk behaviors, substance abuse.

\section{Limitations}

This study had several limitations. The first was that participants who tested positive for HBV were excluded from the study. This exclusion limited the generalizability of the results to a more general homeless population. Because most of the study population was male, the results may not reflect women's patterns of HIV-related behaviors and caution must be used when applying these results to formerly incarcerated, homeless women. Finally, the findings reflect a West Coast perspective and most of the study variables were based on self-report and subject to well-known biases. Nonetheless, the socio-demographic characteristics of the sample are representative of previous studies of homeless adults in California (Masson et al. 2004; Reback et al. 2007; Weiser et al. 2006; White et al. 2006). Furthermore, the overall, findings from this study are congruent with prior investigations on ex offender community re-entry outcomes, in that ex-offenders are at risk for continuing substance abuse, $\mathrm{HCV}$ and HIV co-infection, and limited well being (Caton et al. 2005; Cooke 2004; Lennings et al. 2006).

\section{Conclusions}

Individuals with a dual history of incarceration and homelessness are at greater risk of engaging in behaviors, e.g. substance abuse that increase their chance for HIV infection. These individuals also have sporadic and inconsistent access to substance abuse treatment and public assistance. Both drug and alcohol treatment and increased stability via financial support can reduce risk for HIV infection and, thereby, improve health outcomes in this population, one of society's most vulnerable and marginalized. Therefore, research and policy should direct attention to further integration of resources during and after incarceration. Social services, public assistance and substance abuse treatment should be available to these individuals over longer term and accessible regardless of parole or probation status.

Acknowledgment This manuscript was supported by funds from NIDA Grant \#DA0161-47-01

Open Access This article is distributed under the terms of the Creative Commons Attribution Noncommercial License which permits any noncommercial use, distribution, and reproduction in any medium, provided the original author(s) and source are credited.

\section{References}

Anglin, M. D., Longshore, D., Turner, S., McBride, D., Inciardi, J., \& Predergast, M. (1996). Studies of the functioning and effectiveness of treatment alternatives to street crime (TASC) programs. Los Angeles: UCLA Drug Abuse Research Center.

Bailey, A., \& Hayes, J. (2006). Who's in prison? The changing demographics of incarceration. In H. P. Johnson (Ed.), California courts: Population trends and profiles (Vol. 8, no. 1). San Francisco, CA: Public Policy Institute of California.

Bureau of Justice Statistics. (1999). Mental health and treatment of inmates and probationers. Washington: US Dept of Justice.

Bureau of Justice Statistics Bulletin.(2005). In O. J. Programs (Ed.), US Department of Justice: Washington, DC.

Carter, J., Farabee, D., \& Prendergast, M. L. (2006). Methamphetamine use, self-reported violent crime, and recidivism among offenders in California who abuse substances. Journal of Interpersonal Violence, 21, 435-445. doi:10.1177/088626050 5285724.

Caton, C. L., Dominguez, B., Schanzer, B., Hasin, D. S., Shrout, P. E., Felix, A., et al. (2005). Risk factors for long-term homelessness: Findings from a longitudinal study of first-time homeless single adults. American Journal of Public Health, 95(10), 1753-1759. doi:10.2105/AJPH.2005.063321.

Cooke, C. L. (2004). Joblessness and homelessness as precursors of health problems in formerly incarcerated African American men. Journal of Nursing Scholarship, 36, 155-160. doi:10.1111/j.15475069.2004.04013.x.

Desai, R. A., Lam, J., \& Rosenheck, R. A. (2000). Childhood risk factors for criminal justice involvement in a sample of homeless people with serious mental illness. The Journal of Nervous and Mental Disease, 188(6), 324-332. doi:10.1097/00005053-20000 6000-00002.

Ewing, J. A. (1984). Detecting alcoholism: The CAGE questionnaire. Journal of the American Medical Association, 252, 1905-1907. doi:10.1001/jama.252.14.1905.

Fazel, S., \& Danesh, J. (2002). Serious mental disorder in 23, 000 prisoners: A systematic review of 62 surveys. Lancet, 359(9306), 545-550. doi:10.1016/S0140-6736(02)07740-1.

Ford, W. L. (1992). Risk assessment for IV drug users not in treatment. AIDS Epidemiology Program. Los Angeles: Dept of Health Services. Unpublished Instrument.

Gelberg, L., Gallagher, T. C., Andersen, R. M., \& Koegel, P. (1997). Competing priorities as a barrier to medical care among homeless adults in Los Angeles. American Journal of Public Health, 87(2), 217-220. doi:10.2105/AJPH.87.2.217. 
Glaser, J. B., \& Greifinger, R. B. (1993). Correctional health care: A public health opportunity. Annals of Internal Medicine, 118(2), 139-145.

Greenberg, G. A., \& Rosenheck, R. A. (2008a). Homelessness in the state and federal prison population. Criminal Behaviour and Mental Health, 18(2), 88-103. doi:10.1002/cbm.685.

Greenberg, G. A., \& Rosenheck, R. A. (2008b). Jail incarceration, homelessness, and mental health: A national study. Psychiatric Services (Washington, D.C.), 59(2), 170-177. doi:10.1176/appi. ps.59.2.170.

Hammett, T. M., Harmon, M. P., \& Rhodes, W. (2002). The burden of infectious disease among inmates of and releasees from US correctional facilities. American Journal of Public Health, 92(11), 1789-1794. doi:10.2105/AJPH.92.11.1789.

Harrison, P. M. (2003). Prison and jail inmates at midyear 2002. Washington: Bureau of Justice Statistics.

Health Cost and Services Utilization Study. (1995). Patient baseline questionnaire. RAND Corp. Revised Module 2-13, 15 Dec.

Ke, K. (1998). American jails: looking to the future. ButterworthHeinemann (Ed.), Woburn, MA.

Khan, A. J., Simard, E. P., Bower, W. A., Wurtzel, H. L., Khristova, M., Wagner, K. D., et al. (2005). Ongoing transmission of hepatitis B virus infection among inmates at a state correctional facility. American Journal of Public Health, 95(10), 1793-1799. doi:10.2105/AJPH.2004.047753.

Kushel, M. B., Vittinghoff, E., \& Haas, J. S. (2001). Factors associated with the health care utilization of homeless persons. Journal of the American Medical Association, 285(2), 200-206. doi:10.1001/jama.285.2.200.

Kushel, M. B., Hahn, J. A., Evans, J. L., Bangsberg, D. R., \& Moss, A. R. (2005). Revolving doors: Imprisonment among the homeless and marginally housed population. American Journal of Public Health, 95, 1747-1752. doi:10.2105/AJPH.2005. 065094.

Lee, J., Vlahov, D., \& Freudenberg, N. (2006). Primary care and health insurance among women released from New York City jails. Journal of Health Care for the Poor and Underserved, 17(1), 200-217. doi:10.1353/hpu.2006.0028.

Lennings, C. J., Kenny, D. T., \& Nelson, P. (2006). Substance use and treatment seeking in young offenders on community orders. Journal of Substance Abuse Treatment, 31, 425-432. doi:10.1016/ j.jsat.2006.05.017.

Macalino, G. E., Vlahov, D., Sanford-Colby, S., Patel, S., Sabin, K., Salas, C., et al. (2004). Prevalence and incidence of HIV, hepatitis $\mathrm{B}$ virus, and hepatitis $\mathrm{C}$ virus infections among males in Rhode Island prisons. American Journal of Public Health, 94(7), 1218-1223. doi:10.2105/AJPH.94.7.1218.

Martell, D. A., Rosner, R., \& Harmon, R. B. (1995). Base-rate estimates of criminal behavior by homeless mentally ill persons in New York City. Psychiatric Services (Washington, D.C.), 46(6), 596-601.

Masson, C. L., Sorensen, J. L., Phibbs, C. S., \& Okin, R. L. (2004). Predictors of medical services utilization among individuals with co-occurring HIV infection and substance abuse disorders. AIDS Care, 16, 744-755. doi:10.1080/09540120412331269585.

Metraux, S. C. D. (2004). Homeless shelter use and reincarceration following prison release: Assessing the risk. Criminal Public Policy, 3, 201-222.

Morbidity and Mortality Weekly Report (MMWR). (2004). Transmission of hepatitis B virus in correctional facilities-Georgia, January 1999-June 2002. MMWR, 53(30), 678-681.

Nyamathi, A. (1989). Comprehensive health seeking and coping paradigm. Journal of Advanced Nursing, 14, 281-290. doi: 10.1111/j.1365-2648.1989.tb03415.x.

Pogorzelski, W., Wolff, N., Pan, K. Y., \& Blitz, C. L. (2005). Behavioral health problems, ex-offender reentry policies, and the
"Second Chance Act". American Journal of Public Health, 95, 1718-1724. doi:10.2105/AJPH.2005.065805.

Radloff, L. (1977). The CES-D scale: A self-report depression scale for research in the general population. Applied Psychological Measurement, 1, 385-401. doi:10.1177/014662167700100306.

Reback, C. J., Kamien, J. B., \& Amass, L. (2007). Characteristics and HIV risk behaviors of homeless, substance-using men who have sex with men. Addictive Behaviors, 32, 647-654. doi:10.1016/ j.addbeh.2006.06.008.

Ritchey, F. J., La Gory, M., Fitzpatrick, K. M., \& Mullis, J. (1990). A comparison of homeless, community-wide, and selected distressed samples on the CES-Depression Scale. American Journal of Public Health, 80, 1384-1386. doi:10.2105/AJPH.80.11.1384.

Ruiz, J. D., Molitor, F., Sun, R. K., Mikanda, J., Facer, M., Colford, J. M., Jr, et al. (1999). Prevalence and correlates of hepatitis C virus infection among inmates entering the California correctional system. The Western Journal of Medicine, 170(3), 156-160.

Sherbourne, C. D., \& Stewart, A. L. (1991). The MOS social support survey. Social Science \& Medicine, 32, 705-714. doi:10.1016/ 0277-9536(91)90150-B.

Simpson, D., \& Chatham, L. (1995). TCU/DATAR forms manual. Ft. Worth: Institute of Behavioral Research, Texas Christian University.

Solomon, L., Flynn, C., Muck, K., \& Vertefeuille, J. (2004). Prevalence of HIV, syphilis, hepatitis B, and hepatitis C among entrants to Maryland correctional facilities. Journal of Urban Health, 81(1), 25-37. doi:10.1093/jurban/jth085.

Stewart, A. L., Hays, R. D., \& Ware, J. E., Jr. (1988). The MOS shortform general health survey. Reliability and validity in a patient population. Medical Care, 26, 724-735. doi:10.1097/00005650198807000-00007.

Taxman, F. S., Perdoni, M. L., \& Harrison, L. D. (2007). Drug treatment services for adult offenders: The state of the state. Journal of Substance Abuse Treatment, 32, 239-254. doi:10.1016/j.jsat. 2006.12.019.

Teplin, L. A. (1990). The prevalence of severe mental disorder among male urban jail detainees: Comparison with the Epidemiologic Catchment Area Program. American Journal of Public Health, 80(6), 663-669. doi:10.2105/AJPH.80.6.663.

Teplin, L. A., Abram, K. M., \& McClelland, G. M. (1996). Prevalence of psychiatric disorders among incarcerated women. I. Pretrial jail detainees. Archives of General Psychiatry, 53(6), 505-512.

Travis, J. (2005). But they all come back: Facing the challenges of prisoner reentry. Washington: Urban Institute.

Turley, A., Thornton, T., Johnson, C., \& Azzolino, S. (2004). Jail drug and alcohol treatment program reduces recidivism in nonviolent offenders: A longitudinal study of Monroe County, New York's Jail Treatment Drug and Alcohol Program. International Journal of Offender Therapy and Comparative Criminology, 48, 721-728. doi:10.1177/0306624X04265088.

Visher, C.A., Naser, R.L., Baer, D., \& Jannetta, J. (2005). In need of help: Experiences of seriously ill prisoners returning to Cincinnati. Washington, D.C.: Urban Institute. Washington: US National Commission on AIDS.

Weinbaum, C., Lyerla, R., \& Margolis, H. S. (2004). Prevention and control of infections with hepatitis viruses in correctional settings. $M M W R, 52$ (RR01), 1-33.

Weiser, S. D., Riley, E. D., Ragland, K., Hammer, G., Clark, R., \& Bangsberg, D. R. (2006). Brief report: Factors associated with depression among homeless and marginally housed HIV-infected men in San Francisco. Journal of General Internal Medicine, 21, 61-64. doi:10.1111/j.1525-1497.2005.0282.x.

White, M. C., Chafetz, L., Collins-Bride, G., \& Nickens, J. (2006). History of arrest, incarceration and victimization in communitybased severely mentally ill. Journal of Community Health, 31, 123-135. doi:10.1007/s10900-005-9005-1. 